\title{
ФЕНОМЕН ТЕЛЕПАТИИ С ТОЧКИ ЗРЕНИЯ ФИЛОСОФИИ АНТИЯЗЫКА
}

\begin{abstract}
Аннотация. В статье рассматривается такой феномен человеческой психики, как телепатия. Под телепатией нами понимается мысленное общение между двумя коммуникантами без использования каких-либо опосредующих способов связи. Объектом исследования является телепатическая коммуникация, а предметом исследования - антиязыковой аспект такой коммуникации. Наряду с материалистической трактовкой телепатии применяется широкий (пара)психологический и философский подходы, которые дополняют технонаучный взгляд. Автор подробно рассматривает такие аспекты темы, как виды телепатии, принцип «изначального опоздания», технологии чтения мыслей, нелживая коммуникация.

В статье используются такие методы, как: антиязыковой, герменевтический, деконструктивистский, историко-философский, критический, лингвистический (семиотический), психологический, эвристический. Новизна исследования заключается в том, что для изучения феномена телепатии автор применяет новый антиязыковой метод, благодаря которому удаётся проблематизировать телепатическую коммуникацию с позиции принципа "изначального опоздания». Намечено обоснование новых классов антислов, конкретизирующих семиотический материал той информации, которая может передаваться телепатическим путём. Ключевые слова: Соссюр, Анохин, чтение мысли, принцип, Деррида, философия антиязыка, Золотов, телепатия, нелживая коммуникация, парапсихология.

Review. The article is devoted to telepathy as the phenomenon of human psyche. Telepathy is understood as the mental communication between two communicators without using any mediating means of communication. The object of the research is the telepathic communication, the subject of the research is the anti-language aspect of such communication. Along with the materialistic interpretation of telepathy, the author has also applied the broadside (para)psychological and philosophical approaches, which complete the technoscientific approach. The author examines such aspects of the topic as kinds of telepathy, 'initial delay' principle, mind reading technology and nonfalse communication. In his research article Nilogov has used the following methods: anti-language, hermeneutical, deconstructivist, historical-philosophical, critical, linguistic (semiotic), psychology and heuristic methods. The novelty of the research is caused by the fact that to study the phenomenon of telepathy the author has applied the new anti-language method which allows to problematize telepathic communication from the point of view of the 'initial delay' principle. Nilogov has also provided grounds for describing new classes of anti-words specifying semiotic materials of the kind of information that can be conveyed through telepathy.
\end{abstract}

Key words: Zolotov, philosophy of anti-language, Derrida, principle, mind reading, Anokhin, Saussure, telepathy, nonfalse communication, parapsychology.

\section{I. Телепатический калейдоскоп}

С феноменом телепатии (общение между сознаниями на расстоянии) мы уже имели дело в статье, посвящённой бессловесной коммуникации Джона Беннета [1]. В ней мы, в частности, привели аргументы в пользу того, чтобы трактовать это явление с позиции философии антиязыка. Ведь сегодня технонаука вплотную подступила к практическому решению проблемы телепатической коммуникации, видимо, так же предвзято, как и к проблеме искусственного интеллекта, внедряемого повсеместно без чёткого представления о том, что такое человеческий интеллект как составляющая часть сознания. Тем не менее, ещё в советское время ака- демик-математик Евгений Васильевич Золотов в рукописи учебника изложил свою материалистическую телепатическую технологию будущего [2].

По мнению Е.В. Золотова, изучение закономерностей телепатии применительно к живым разумным существам невозможно без знания таких наук, как кибернетика (которая понимается как наука о связи организма со средой и другими организмами на основе энергетического обмена), ядерная физика, включая теорию поля, радиационная биология и медицина, высокомолекулярная химия, генетика, психология [2]. Телепатия, по Золотову, - это энергетический процесс обмена информацией, имеющий прямое физиологическое обоснование (ср.: [3]). Золотов также признал приоритет в этом 


\section{Психология и психотехника 11(86) • 2015}

вопросе со стороны психологов и философов, которые поначалу объясняли телепатические явления идеалистически - с точки зрения сверхъестественных сил (Мировой дух, душа), - однако, начиная с XIX в., стали постепенно использовать материалистическую теоретическую базу. По словам Золотова, такое положение дел было связано с тем, что отсутствовали необходимые фундаментальные данные о строении материи и видах её движения, да и сами естественные науки того времени отставали от потребностей нашего человеческого ума в обобщении и объяснении наблюдаемых явлений. Ложный путь идеализма обернулся для философии тем, что от неё отвернулись почти все естественные и точные науки, тогда как рост материалистических объяснений явлений природы всё возрастал. Философия и скоропалительно выделившаяся из неё экспериментальная психология так и остались в этом вопрос не у дел...

Поэтому мы и решили восполнить психологофилософское рассмотрение феномена телепатии в рамках разрабатываемой философии антиязыка. Но прежде, как советовал Рене Декарт, договоримся о терминах. В одном философском интернетсловаре находим следующее определение телепатии: «Телепатия (от греч. tele - вдаль, далеко и pathos - чувство) - передача мыслей и чувств на расстоянии без посредства органов чувств, то есть без помощи языка, непроизвольного шепота или каких-либо чувственно воспринимаемых явлений, выражающих внутреннюю жизнь человека. Наука всё больше и больше допускает возможность такого процесса» [4].

Однако существует и другая точка зрения, согласно которой всё эксперименты с телепатией с трудом находят признание в науке, ведь до сих пор такие экстрасенсорные феномены, как пророчество, телепатия и ясновидение, составляют предмет исследования парапсихологии [5], а не психологии. (К слову, сам термин «телепатия» был впервые употреблён в 1882 г. английским психологом Фредериком Майерсом - сооснователем Общества психических исследований.) По данным Википедии, «Телепа́тия (от др.-греч. $\tau \tilde{\eta} \lambda \varepsilon$ - «далеко, вдали» и $\pi \alpha ́ \theta 0 \varsigma$ - «чувство») - не имеющая надёжных экспериментальных доказательств гипотетическая способность мозга передавать мысли, образы, чувства и неосознаваемое состояние другому мозгу или организму на расстоянии, либо принимать их от него, без использования каких бы то ни было известных средств коммуникации или манипуляции» [6] (см. также: [7; 8; 9; 10; 11; 12]).

Существует несколько видов телепатии: например, сознательная телепатия (передача мысли на расстоянии) и бессознательная телепатия (собственно телепатия). Именно телепатия во многом развела парапсихологов и спиритуалистов, так как стала пониматься в качестве средства общения даже тогда, когда на сознательном уровне подобных попыток не предпринимается. Парапсихологи пошли материалистическим экспериментальным путём, а спиритуалисты остались на идеалистической точке зрения, понимая телепатию как общение с потусторонними силами.

«Энциклопедия оккультизма и парапсихологии» проводит принципиальное различие между телепатией и передачей мысли на расстоянии: «При телепатическом <общении> передающая сторона может не знать о том, что действует как агент и принимающая сторона не готовит себя сознательно к приёму мысли. Телепатия не может быть объектом эксперимента, в то время как передача мысли на расстоянии - может. Передача мысли - рудиментарное свойство. Телепатия - высокоразвитый режим паранормального восприятия и обычно <её механизм> приводится в действие сильными чувствами» [6]. Впрочем, не все парапсихологи придерживаются такого разделения. Также выделяются телепатии по передаче информации: ретрокогнитивная (прошлое), прекогнитивная (будущее) и интуитивная (настоящее).

\section{II. Антиязыковая методология для телепатии}

На наш взгляд, мечта о телепатическом общении может быть объяснена тем, что коммуникация посредством естественного языка никогда в полной мере не удовлетворяла людей. Этому можно найти множество разных причин, но, избрав философский подход, мы должны зрить в корень проблемы, а он заключается в фундаментальной критике естественного человеческого языка и сопутствующих ему явлений. Необходимо революционизировать тот лингвистической поворот в философии, который произошёл в XX в. на волне критики метафизики, за счёт антиязыкового переворота всей истории философии.

Перспектива методологического обоснования этого нового синергетического знания позволяет определить предмет философии антиязыка следующим образом: изучение оснований и пределов семиотической номинации на человеческом языке и зависимости познавательного процесса от антиязыка [13]. Обозначив предметное поле философии антиязыка, мы пока не берёмся устанавливать её объект, так как считаем, что в первую очередь нужно закрепить её в качестве нового раздела философии (или - на первом эта- 
пе - в качестве подраздела философии языка), в котором будут выявляться собственно и несобственно антиязыковые дискурсивные практики. Под первыми понимается поиск таких классов антислов, которые par excellence невыразимы в естественном человеческом языке (постулирование - с подачи Золотова - таких классов антислов, как ретроскопологизмы и проскопологизмы [2], а также ретрологизмов и футурологизмов), а под вторыми - критика существующих способов коммуникации и сигнификации посредством естественного человеческого языка (апологетика и критика принципов «изначального опоздания» и «изначального опережения»). Рабочая дефиниция антиязыка такова: система (совокупность) классов антислов, которые представляют соответствующие области частично или полностью не поименованного бытия.

Феномен телепатической коммуникации является важной проблемной областью философии антиязыка, так как благодаря телепатии возможно преодолеть лживость и неподлинность общения между людьми. Конечно, если договориться до такого абсурдного тезиса о том, что язык существует лишь для того, чтобы скрывать свои настоящие мысли (Гиренок), то языковая коммуникация (как обмен пустыми знаками, по Гиренку) вообще может подорвать собой весь фундамент естественного человеческого языка [14]. Учитывая тот факт, что язык как знаковая система выполняет две основополагающие функции - именования и общения, на огромном лингвистическом материале приходится признать, что и номинативная функция языка, постоянно соприкасаясь с неименуемым и неозначиваемым, рискует рано или поздно саморазоблачиться. А если ещё упомянуть о проблеме загрязнённости мышления и, в целом, сознания - языком, не допускающим нена-слеж-енное неязыковое состояние иных форм мышления (за исключением, быть может, жестового языка глухонемых?), то приходится смириться перед тотальностью Языка, засевшим в нашем головном мозге подобно вирусу (ср.: английский психиатр Т. Кроу в своей работе «Is schizophrenia the price that Homo sapiens pays for language?» [15] высказал идею о том, что шизофрения может являться той ценой, которую человек платит за язык; отечественный филолог В.П. Руднев также склонен положительно отвечать на этот вопрос [16]).

Мы отдаём себе отчёт в серьёзности сделанных предположений и, забегая далеко вперёд, укажем на те первоочередные проблемы, которые планируем изучать в философии антиязыка:
1) номинацию (именование) того, что в принципе невыразимо в естественном человеческом языке (для внешних вещей-референтов);

2) номинацию (именование) того, что невыразимо в естественном языке человеческими каналами получения информации (то, что лежит по ту сторону человеческого способа существования);

3) номинацию (именование) того, что в целом пытается вырваться за ограничивающий принцип «изначального опоздания» (действие принципа «изначального опережения»), присущий всем семиотическим (различающим от «différance») системам.

Следовательно, под самим антиязыком будем понимать:

1) естественный человеческий язык в качестве языка как такового;

2) естественный человеческий язык в качестве именно человеческой разновидности языка как такового;

3) естественный человеческий язык, не пригодный для номинации вообще всего того, что подпадает под принцип «изначального опоздания».

Приступая к анализу феномена телепатии с позиции философии антиязыка, необходимо показать, какой фундаментальный изъян существует в нетелепатической коммуникации посредством обычного языка, а затем привести аргументы в пользу телепатического общения. Несмотря на околонаучный антураж изучаемых явлений, современный информационный подход уже позволил объединить пророчество и телепатию, понимая под первым мысленное общение людей, разделённых во времени, а под вторым - мысленную коммуникацию людей, разделённых в пространстве. Конечно, учёные отрицают биологические предпосылки к телепатии, считая её принципиально невозможной, тем не менее, мы хотим доказать, что телепатические исследования не следует относить к псевдонаучной деятельности, по крайней мере, в рамках самой философии и её раздела - философии психологии.

Чтобы показать приоритет телепатического общения над обычной коммуникацией, необходимо доказать, что посредством телепатии возможно преодоление задержки в передачи и получении информации за счёт сокращения как звуковой материи языка (означающее), так и понятийной стороны (означаемое). Мы исходим из соссюровской трактовки языкового знака, согласно которой существует план содержания (означаемое) и план выражения (означающее). Несмотря на то, что знак 


\section{Психология и психотехника 11(86) • 2015}

(сема), по Соссюру, это единство акустического образа с понятием $[17$, с. 39,117$]$, между этими планами пролегает очень тонкая проблема нетранспарентности, которая на психологическом уровне сводится к неудовлетворённости от мыслимого и произносимого. Согласно Соссюру, речевая деятельность включает три момента: физический, то есть распространение звуковых волн, физиологический, то есть движение звуковых волн от уха к акустическому образу и от акустического образа к движениям речевых органов, и психологический, то есть сами акустические образы, не совпадающие со звучанием (представление о физическом звучании) и сами понятия. Однако самой фундаментальной остаётся проблема запаздывания плана выражения к плану содержания, а конкретно - на уровне сигнификации (означивания) - в изначальном (а потому фундаментальном) запаздывании плана выражения (означающего) к плану содержания (означаемого), а последнего, в свою очередь, к референту, то есть самой вещи. Таким образом, обозначенная проблема, в конечном счёте, может быть суммирована в принцип «изначального опоздания», который был впервые поставлен в работах французского философа-деконструктивиста Ж. Деррида [18], а терминологически закреплён другим французским философом В. Декомбом [19]. Поскольку мы считаем, что данный принцип пронизывает практически все лингвистические и философские проблемы, постольку он может являться самым фундаментальным вопросом. Речь ни в коем случае не идёт только о частной проблеме перевода человеческих мыслей в словесные оболочки, когда нужно оперативно подыскивать адекватное слово или составлять новое слово для выражения нового смысла, косноязычно мысля вслух. Мы, вслед за Деррида, настаиваем на той фундаментальной задержке, которая была концептуально оформлена в принцип «изначального опоздания».

\section{III. Принципиальность принципа «изначального опоздания»}

Ж. Деррида («Письмо и различие», 1967): «Несомненно, жизнь предохраняет саму себя через повторение, след, отложение. Но нужно осторожно относиться к такой формулировке: нет жизни, которая вначале бы просто существовала и лишь затем стала бы себя защищать, отсрочивать, откладывать в отложении. Откладывание конституирует саму сущность жизни. Или скажем так: откладывание как различение, не представляя из себя ничего, не будучи какой бы то ни было сущно- стью, не будет и жизнью, если бытие определяется как ousia, присутствие, сущность / существование, субстанция или субъект. Нужно помыслить жизнь как след до определения бытия как присутствия. Таково единственное условие, необходимое, чтобы сказать, что жизнь есть смерть, что повторение и та сторона наслаждения изначальны и врожденны тому, за пределы чего они выходят. Когда Фрейд в «Наброске» пишет о том, «что прокладывание путей служит первичной функции», он уже запрещает нам удивляться чему-то в «По ту сторону принципа удовольствия». Он признаёт право двойной необходимости: приурочить откладывание как различение к самому истоку и в том же самом жесте зачеркнуть понятие первичности: теперь мы уже не будем удивляться Traumdeutung'y, определяющему это понятие как «теоретическую фикцию» в параграфе о «запаздывании» (Verspätung) вторичного процесса. Таким образом, запаздывание изначально. Иначе откладывание было бы просто сроком, который даёт себе сознание, присутствие для самого себя как присутствующего в настоящем [что, видимо, возмутительно! - Воскл. А.Н.]. Откладывать - это не значит отсрочивать возможное присутствие, откладывать некий акт, переносить нечто на момент уже и сейчас возможного восприятия. Это возможное возможно только в откладывании, которое, следовательно, необходимо понимать иначе, чем некий расчёт или механику решения. Сказать, что откладывание изначально это в то же время устранить миф присутствующего начала. Вот почему слово «изначальный» нужно понимать через зачёркивание, иначе различение и отложение выводились бы из некоего полного начала. Изначально - не-начало» [19, с. 328-329].

Расшифровка изначальности запаздывания содержится в следующей сноске: «군 понятия изначального откладывания и запаздывания или даже понятие времени немыслимы в логике тождества. Абсурдность, которая обнаруживается в самих этих терминах, если её определённым образом организовать, позволяет мыслить запредельное для этой логики и этого понятия пространство. Под словом «запаздывание» нужно понимать нечто отличное от отношения между двумя моментами «настоящего»; нужно избегать следующего представления: только в настоящий момент В происходит то, что должно (было бы) произойти в (предшествующий) момент А. Понятия изначального «откладывания» и «запаздывания» стали для нас необходимы после прочтения Гуссерля («Введение в «Начало геометрии» Гуссерля» (1962), р. 170-171)» [19, с. 367].

Понятно, что здесь не имеется в виду подмена одного (должного) состояния другим (недолж- 
ным) состоянием, которую бы хотелось помыслить, противореча только что сказанному, однако необходимо тщательней разобраться с этим долженствованием: если долженствующее не случается в определённый момент, то вправе ли мы требовать его осуществления в последующий момент? Видимо, вся загвоздка в том, что этот самый последующий момент имеет собственную аутентичную темпоральность, которая не может выступать в качестве замены предшествующего момента, иначе мы попадаем в закольцованный круг, в котором (sic!) последующий момент В рискует оказаться не истиной предшествующего момента A, а заблуждением третьего момента $C$, играющим на опережение. Ещё раз вчитаемся в отрывок, но, исходя от обратного, представим: «...только в настоящий момент В происходит то, что должно (было бы) произойти в (предшествующий) момент А». Если допустить такое положение, то к чему мы приходим? К этому: мы не можем быть удостоверенными в том, что под моментом В осуществился именно момент A, так как принцип различания (след-ования) не исчерпывается двумя моментами, а представляет собой интенциональный поток без начала и конца, в котором только сама задержка - изначальна по определению Дерриды.

Правда, почему в действительности нельзя допустить того, от чего отговаривает Деррида? Где мы приобретём гарантию аутентичности моментов А и В, если они не являются заменами друг друга? Означает ли такая постановка вопроса, что мы не в состоянии высказать заблуждение в моменте A, так как истина в моменте В сама по себе? В чём, собственно говоря, выражается принцип «изначального опоздания», если его так трудно проиллюстрировать? Или тут надобно подразумевать следующее (далее мы будем фиксировать римскими цифрами те аспекты нашей трактовки дерридеанского неологизма «différance», которые позволяют в перспективе деконструировать, применяя соответствующую методологию, философию языка в философию антиязыка): (I) налагается запрет на подмену одного момента другим моментом, но не запрещается запаздывание одного момента к другому моменту таким образом, при котором неверно утверждать, что последующий момент, будучи запоздалым / запоздавшим, неистинен к предыдущему моменту? Означает ли запаздывание у Дерриды неистинность сменяющих друг друга моментов? Так и хочется ответить утвердительно, подразумевая различение онтологического и онтического уровней (как у Хайдеггера), но Деррида настаивает на принципе следа (différance), который конституирует весь поток без начала и конца, поэтому (II) нет смысла утверждать бинарность истины и заблуждения на примере предшествующего момента А и последующего момента B, учитывая, что до и после существовали моменты, имя которым - Легион. В этом разрезе принцип «изначального опоздания» ещё глубже, ибо означает практически следующее: предшествующий момент А не является истиной последующего момента В, так как внутри любого из этих моментов уже заложено «изначальное опоздание», которое мы плавно (авторски ли?) перевели в проблему семиотической сигнификации (то есть в задачу удостоверения аутентичности момента, который означивается (опредмечивается, опосредуется, но прежде всего - различается) как двусоставная сущность - знак), тогда как сам Деррида отталкивался от рецепций Гуссерля в «Началах геометрии».

Расширительно-семиотически принцип «изначального опоздания» означает следующее: «Репрезентация никогда не может быть элементом настоящего, она лишь следует жизни мира и потому всегда запаздывает по отношению к ней. Выпадение из настоящего времени не позволяет знаку обслуживать, фиксировать, репрезентировать присутствие человека при жизни мира. Существование знака лишается смысла, а знак, в свою очередь, лишается и своего реального существования» [20, с. 77].

Теперь сошлёмся на фрагмент из учебника Д.Э. Гаспарян «Введение в неклассическую философию», в котором данный принцип разбирается достаточно подробно: «Таким образом, выводимое неклассикой Различие призвано быть отличённым от различия, принятого в метафизике. Но сможет ли оно в таком своем исполнении заместить классическое начало, справится ли с ролью бытия началом? Лучше всего охарактеризовать сложившуюся в связи с этим вопросом ситуацию поможет метафора «изначального опоздания», к которой в своих работах неоднократно прибегает Ж. Деррида [жирный мой. - Прим. А.Н.]. Если мы присмотримся к тому, как функционирует Различие, то мы вынуждены будем признать, что нам никогда не удастся добраться до самого начала - когда бы мы ни явились в надежде застать начало, мы всегда будем запаздывать. Это связано с тем, что нам суждено встречаться лишь с результатами работы Различия-начала, но не им самим. Нельзя присутствовать при работе Различия, хотя бы потому, что само Различие никогда не присутствует. Ни в мысли, ни в опыте оно не присутствует так, как метафизика полагала присутствующим свое соб- 


\section{Психология и психотехника 11(86) • 2015}

ственное начало - Бытие-Сущее. Последнее может быть и быть предъ-явленным, ведь оно совпадает с самим собой, является чистым Тождеством. Различие, напротив, не совпадает даже с самим собой. С чем мы тогда вообще намерены встречаться?

Но хотя мы и готовы поставить под сомнение существование Различия, отказывать ему в реальности все-таки невозможно, ибо об этом свидетельствуют его следы, оставленные результаты проведенной им работы. Это как раз те самые квазипредельные категории, с которых было принято начинать в классической метафизике. Их присутствие свидетельствует о том, что никогда не присутствующее в акте непосредственного восприятия начало успешно справилось со своей задачей. Но именно поэтому на встречу с началом можно разве что опоздать. Как бы рано мы ни появились, начало на месте мы не застанем, нам будут явлены лишь следы его отступления. Различие никогда не будет тем самым Различием, оно всегда будет другим, а мы, в свою очередь, как бы старательно к нему ни приближались, всегда будем отброшены назад работой самого различения [жирный мой. - Прим. А.Н.]» [21, с. 332].

Отсюда и возникает эта неудовлетворённость от выражения мыслимого, если мыслимое и выражение понимать как два сменяющих друг друга момента во времени. Сподручно ли мыслимое и выражаемое объединить в один момент времени, внутри которого отмеченная неудовлетворённость объясняется знаковой природой мышления, то есть возникающая в результате трансформации плана содержания в план выражения при помощи сигнификации? Всё-таки, (I) мы располагаем таким «изначальным опозданием», которое характеризуется невозможностью улавливать знаками то содержимое мысли, которое приходится «ословесивать» с техническим (и даже технологическим) запаздыванием к исходной мысли, так как сам процесс протекает во времени путём смены интенций (итеракций, моментов, состояний); да и сама сущность знака предполагает наличие двух планов, как у монеты, орла (плана содержания) и решки (плана выражения). Побочным (если не центральным) следствием такого запаздывания может стать «опережающая номинация», которая всегда готова облечь любую новую мысль в старые словесные оковы; по форме имеем дело с «изначальным опозданием», а по содержанию - с «изначальным опережением», навёрстывающим «изначальное опоздание» в горизонте предвидимой неудовлетворённости от прошлых означиваний.

Терминологически принцип «изначального опоздания» (до)сформулировал другой француз- ский философ В.Декомб в книге «Современная французская философия». Процитируем соответствующий отрывок из книги Декомба, в котором он продолжает ассоциативный ряд по поводу истолкования такого центрального дерридеанского неологизма, как «различание» («différance»): «Понятие «изначального опоздания» парадоксально, но необходимо. Если бы не существовало с самого начала (всякий раз, когда существует начало), с «самого первого раза», то различание, первый раз не был бы «во-первых», поскольку за ним не следовало бы «вовторых»; и если бы «первый раз» был «единственным разом», он не был бы началом ничего. Следует сказать, - и данное утверждение, несомненно, несколько диалектично, но отнюдь не ошибочно, - что первое не будет первым, если за ним не последует второе. Вторичное есть не просто то, что приходит на смену первичному в качестве некоего запоздания, - оно есть то, что позволяет первичному быть первичным. Так, первому не удаётся быть действительно первым только благодаря собственным усилиям, собственным средствам: в этом ему помогает вторичное всей силой своего запоздания. Первое является первым только при содействии второго. «Во-вторых», следовательно, обладает своего рода первичностью по отношению к «во-первых»: с самого начала оно присутствует как предварительное условие первичности «во-первых» (не будучи при этом, естественно, самым изначальным «вопервых» [речь о вторичном. - Прим. А.Н.]: из этого следует, что «во-первых» на самом деле является «в-третьих»)» [19, с. 140]. (Мы продолжили логику Деррида-Декомба (языковая игра до последнего различания!) (см.: $[13$, с. 139,140$])$.)

За этими замысловатыми пассажами скрывается вся подноготная современной философии и её центрального раздела - онтологии, которая как учение о сущем уже не может претендовать на дескрипцию сущего, а метафизика - на дескрипцию бытия (в хайдеггеровском различении бытия как онтологического и сущего как онтического), потому что фундаментальность принципа «изначального опоздания» постулирована самой семиотичностью - знаковой природой человеческого познавательного процесса.

В. Декомб: «В ещё более общем плане настоящее является настоящим лишь при условии, что оно соотносится с отсутствующим, дабы стать отличным от него (отличным от отсутствующего, которое есть прошлое или будущее). По Деррида, метафизика могла бы быть жестом стирания этой отличающей метки, этого следа отсутствующего, следа, благодаря которому настоящее есть настоящее. В таком случае можно заметить следующее: 
след обычно означает наличествующий знак отсутствующей вещи, знак, оставленный этим отсутствующим после его перемещения туда, где оно наличествовало; но если всякое наличествующее несёт след отсутствующего, его ограничивающего (и в этом смысле его конституирующего, продуцирующего, придающего ему бытие, каковым это наличествующее является), то тогда следует парадоксальным образом помыслить «изначальный след», то есть наличествующий след прошлого, никогда не имевшего места: “абсолютного прошлого" ${ }^{11}{ }^{1}$ Derrida J. De la grammatologie. P. 97 (см. также: Freud et la scène de l'écriture // Ecriture et différence. P. 293 et sq; мы обнаруживаем здесь «изначальное прошлое» Мерло-Понти))» [19, с. 143].

Или, другими словами: (II) если наличествующий момент В является следом уже отсутствующего момента A, то тогда момент В содержит в себе прошлое момента A, которое придаёт моменту В бытие, и, следовательно, момент В не может целиком передать момент А (его истину), почему и налагается запрет на мыслимость истины уже отсутствующего момента А в истине-следе момента В, который в свою очередь зависит от момента С и т.д.

В. Декомб: «"В начале - повторение”. «В начале - представление»: и, следовательно, не существует даже репрезентации, поскольку презентация (напоминанием о которой служит данная репрезентация) никогда не имела места. Оригинал уже является копией. Мы имеем здесь дело с «принципом не-принципа», при помощи которого Деррида деконструирует гуссерлевский «принцип принципов», ведь последний основан на постоянном отличии оригинала (интуиции, называемой «изначально дающей» самою вещь собственной персоной) и производного продукта (интенции сознания, не осуществлённые с помощью интуиции). Другой версией того же «принципа не-принципа» можно считать «В начале - знак». Знак, а не вещь (референт), знаком которой призван быть данный знак. Этой семиологической версии Деррида уделял особое внимание в силу различных причин, самая важная из которых, несомненно, заключается в том, что она разрушает все претензии в то время очень распространённой семиологии, уничтожая возможность изолировать «знак» и «референт». Существуют два подхода к этой семиологической версии. Один из них состоит в прямой радикализации феноменологии. Доказывая в противовес Гуссерлю, что сознание никогда не предшествует языку, можно прийти к выводу, что последний не может считаться «выражением» (репрезентацией) молчаливого «переживаемого» (изначальной презентации). Таков путь, которым следует работа “Голос и феномен”» [19, с. 140-141].

\section{III. Телепатия как панацея?..}

Теперь зададимся следующим вопросом: является ли телепатия как «мысленная коммуникация между двумя индивидуумами без использования каких-либо очевидных способов связи» [5, с. 22] панацеей от «изначального опоздания»? При первом приближении напрашивается положительный ответ, ведь чисто физически (акустически) при телепатии устраняется звуковая сторона знака (означающее), которая, будучи в некотором смысле произвольной, добавляет задержку, усугубляя и без того принцип «изначального опоздания». Если телепатия как энергетический обмен информацией не нуждается в посредничестве языка, то благодаря ей экономятся многие усилия по воязыковлению мышления и передаче его другому телепату. В этом случае содержание телепатемы не зависит от фонетической составляющей традиционного речевого знака, а передаётся, пускай и не непосредственно, а в обрамлении языка мысли, который в той или иной выигрывает (компенсирует) нам фундаментальность «изначального опоздания». (Стоит обратить внимание на некоторую контекстуальную некорректность между «компенсировать» и «фундаментальность изначального опоздания».) С другой стороны, физическая (энергетическая) передача информации (энергии) всегда протекает во времени, а потому имеет темпоральную константу, хотя бы ограниченной такой космологической константой, как скорость света. Ведь запаздывает не только означающее к означаемому, а вообще любая передача сигнала от индуктора к приёмнику: например, фотоны от Солнца доходят до Земли за 8 минут и 20 секунд, а радиосигнал с Земли до Марса идёт от 3 минут и 6 секунд до 22 минут и 17 секунд в зависимости от расположения орбит планет (в среднем - 15 минут). Так, в 2010 г. российский президент Д.А. Медведев, находясь с визитом в канадском городе Хантсвилл, общался по видеосвязи с Москвой и посетовал на то, что сигнал по российским каналам видеосвязи идёт с 3-4-секундным замедлением, в то время как в Кремниевой долине (США) такой задержки нет [22].

Здесь будет уместным вновь сослаться на Е.В. Золотова, который приводит следующую психофизиологическую аргументацию: «Все физиологические процессы при использовании энергии в любых телепатических упражнениях резко тормозятся; «износ» тела прекращается - человек в это время «не живёт» - в физиологическом смысле, он оказывается «вне времени». Действительно, воспринимая информацию в образах и звуках, скажем, 


\section{Психология и психотехника 11(86) • 2015}

из II в до н.э., мы убеждаемся, что она сохранилась «для нас» в девственно чистом виде, что мы в состоянии воспринимать её без всякого искажения [речь о ретроскопии. - Прим. А.Н.]. Те же соображения можно высказать и в отношении восприятия информации из будущего [речь о проскопии. - Прим. A.H.]. Конечный результат, выраженный математически кибернетической системой на дискретных началах, не будет менее чётким, туманны, «размытым» или «размазанным» из-за того, что событие, о котором мы получили информацию от машины, произойдёт (если мы того пожелаем и запустим модель процесса в производство) через несколько дней, месяцев, лет» [2].

Да, теория телепатии с материалистической позиции - это, по Золотову, теория биомагнитного или гравитационного поля, как и сами закономерности телепатии - это закономерности поля [2]. Однако существует ли другая - нематериалистическая трактовка? Психофизиология - тоже материализм, несмотря на то, что в термине присутствует «廿uхи́» (душа), правда, сдаётся нам, что современная психология - это не столько наука о душе, сколько наука о психике, то есть анатомически - о нервной системе живого организма. Нам также несподручно разочаровывать парапсихологов и прочих шарлатанов от психологии (например, телевизионных загримированных экстрасенсов), понимая под телепатией нечто непознаваемое. Но, с другой стороны, широкий психолого-философский подход позволяет нам гипотетически предложить восполнительные интерпретации феномена телепатии, которые невозможно свести ни к историческим случаям телепатических практик (например, Г.И. Гурджиев [1]), ни к современным техническим приборам по чтению мыслей (например, компьютерная программа, которая способна распознавать слова, не высказанные вслух) [23].

Несомненно, «изначальное опоздание» при телепатии не может быть устранено полностью, поскольку сохраняется независимость языка мысли. Телепатический гипноз или телепатическое зомбирование человека может быть доступно только в том случае, если удастся контролировать весь феноменологический поток сознания, не размениваясь на погрешности аутентичности, а также созидая силой мысли вещи во внешнем мире (ср.: [24, c. 109]). Несмотря на то, что телепатия протекает во времени, принцип «изначального опоздания» неизбежно оставляет свои следы, подразумевая статистическую погрешность на примере взаимной телепатии [25, с. 247].

«Изначальное опоздание» при телепатии не является панацеей непосредственной координа- ции между планом содержания и планом выражения, поскольку трудно отрицать воязыковление мысли, то есть общение исключительно языком мышления, а не словами (если телепатия имеет градацию, то воязыковление может быть поставлено под нериторический вопрос, требующий проблематизации языка мысли - например, в фодоровской теории. С другой стороны, при телепатии невозможно полностью отказаться от «изначального опоздания»: синхрония между мыслью и озвуковлением предполагает константность как мысли, так и означающего, в то время как интенциональная природа сознания пригодна только для диалектической течки. Природа мысли, воязыковляемой во времени, носит изначально запаздывающий характер, который не поддаётся верификации из-за однотипной точности измерительных приборов: семантическая нищета понимания, основанная на принципе «изначального опоздания», бросает вызов онтологии присутствия / отсутствия с точки зрения презумпции перформативного парадокса, при которой прорыв к означаемым, минуя означающие, не приводит к инстанции истины или фальсификации внутри бинаризма «присутствие отсутствие», а указывает на семиотическое равнодушие при апеллировании к тождеству небытия и мышления. Если телепатия и может быть очищена от семиотических напластований (от означаемого и означающего), вместо которых удастся определить другие единицы коммуникации, то тогда миф об «изначальном опоздании» будет развеян в онтологическую константу.

\section{Tелепатическое, слишком телепатическое}

Наше антиязыковое решение вопроса об «изначальном опоздании» предполагает не только редукцию человеческой коммуникации к телепатии, но и собственно критику такой редукции и самого «изначального опоздания».

Поставим под вопрос экономическую трактовку телепатии (как с позиции принципа «изначального опоздания», так и с позиции психофизиологических усилий). Овладение антиязыком вовсе не предполагает экономию на звуковой материи языка, чтобы исключить «изначальное опоздание», а располагает дальше телепатической коммуникации, оптимально смещённой к божественному языку. Не зря телепатию и понимали расширительно как молитву, то есть как попытку общения с Богом, впрочем, не исключено, что наряду с этим нужно не забывать о таких феноменах, как самовнушение и самообман. Чтение мыслей ещё до их воязыковления может завершиться разоблачением всех ма- 
нипуляций сознания, поскольку окажется вероятной коммуникация с самим Богом: например, при злокозненном внушении, отчуждающем практику человекообожествления до неразличения теизма и атеизма; неидеологическое управление мышлением сводится к контролю над самостью, идентифицирующей свободу с мерой самоотчуждения (см.: [26]).

Симптоматично даже не то, что телепатия воспринимается как панацея (иначе как объяснить психологическую обеспокоенность по поводу повсеместного виртуального общения?), а то, что сегодня телепатия мыслится в качестве расширения человеческого потенциала за счёт киборгического сращения с техникой, намного лучше считающей, пишущей и читающей, а в перспективе, в том числе, и мысли других людей-киборгов. Если техническим решением телепатического вопроса станет непременное имплантирование в головной мозг человека соответствующего прибора (например, чипа), который будет преобразовывать нейросигналы и передавать их другому прибору-человеку (так называемые мозгомашинные интерфейсы), то об антропоразмерной телепатии придётся раз и навсегда забыть (да и стоит ли скорбеть по этой псевдоатавистической иллюзии?). Причём данные нейроинженерные ноу-хау разрабатываются, в первую очередь, для слепоглухонемых людей, помогая им преодолеть физические недуги. Но удивительно здесь то, что устраняя инвалидность для отдельных людей, мы рискуем превратить всё человечество в одного большого инвалида, который со временем утратит все человеческие, слишком человеческие качества, став не сверхчеловеком (как мечтал Ницше), а обыкновенным киборгом - получеловеком-полуроботом. (Так, например, американский футуролог и технический директор компании Google Рэй Курцвейл в конце 2015 г. сделал прогноз о развитии человечества и его технологий аж до 2099 г., предсказав к 2045 г. наступление тотальной техносингулярности, в результате которой планета Земля превратится в один суперкомпьютер (см.: [27]).)

Следя за развитием этих чудо-технологий, можно констатировать, что научно-технический прогресс налицо. Так, например, ещё в 2004 г. учёные НАСА [23] создали компьютерную программу, которая считывает с помощью датчиков под подбородком и по обеим сторонам адамова яблока нервно-мышечные сигналы, которые посылаются головным мозгом языку, горлу и голосовым связкам (наподобие электромиографических исследований работы голосовых связок во время трудных мыслительных операций [28, с. 323-334]). А уже в
2007 г. прорывом стало чтение желаний и намерений человека с помощью аппарата магнитно-резонансной томографии, когда путём сканирования активности мозга удавалось распознавать то, что человек думает в определённый момент времени (магнит «чувствует» железо в гемоглобине, которое несёт кислород, что позволяет увидеть, какие именно нейроны активированы) [29]. Причём в последнем случае эксперименты продемонстрировали уникальное свойство работы нашего мозга, когда намерение человека (например, прибавить или отнять) становилось ясно ещё до того, как он скажет об этом. Получилось фиксировать намерения ещё до того, как они словесно сформулированы (ср. с экспериментами американского нейрофизиолога А.Р. Дамазио [30]).

Подобные разработки и внедрения ведутся на протяжении десятков лет (работы Мигеля Николелиса, Джона Донахью, Уильяма Фрея, Дэвида Фостера, Мэтью Уилсона и др.) [31], в том числе и отечественными учёными - например, нейробиологом К.В. Анохиным, одно из интервью с которым так и озаглавлено: «Чтение мыслей станет реальностью» [31]. Приведём соответствующую цитату: «Если говорить об использовании интерфейсов для декодирования мыслей, то в данном случае, по мнению Константина Анохина, мозгомашинные интерфейсы целесообразно разделять на два вида: «поверхностные» и «глубокие». Первые регистрируют суммарные сигналы с поверхности черепа. Вторые - сигналы от одиночных нейронов мозга, для чего требуется проникновение электродов (устройств с чипами) в глубину мозга.

«Для эффективного использования поверхностных интерфейсов практически не нужно понимать нейрофизиологическую природу мышления, - отмечает Константин Анохин. - Сегодняшние интерфейсы являются яркой иллюстрацией этого тезиса. Мы до сих пор не понимаем природу мышления, однако имеем работающие интерфейсы». <...>

Важнейшие решения в этой области - разработка технологий, которые будут соединять задачи построения интерфейсов и изучения глубоких процессов активности отдельных клеток головного мозга. Именно это сделает возможным считывание мыслей как объективный процесс» [31].

В этих словах больше всего поражает то, что для мысленного управления с помощью электродов той или иного устройства вовсе не обязательно знать нейрофизиологическую природу самого процесса мышления... Какой когнитивный парадокс! Настоящий скандал в философии сознания!.. 


\section{Психология и психотехника 11(86) • 2015}

\section{V. Критика телепатического разума}

Мы отдаём себе отчёт, на каком уровне аргументации ведётся наше обсуждение поставленной проблемы и её сциентистское (нейрофизиологическое) решение. Успехи технонейронауки многообещающи и, кажется, впечатляющи, однако это вряд ли уже судьба традиционного телесного человека, который по всем фронтам сдаёт свои позиции, уступая место трансгуманистическому нановеществу (см.: [32]). Тем не менее, мы продолжим гнуть свою исследовательскую линию в направлении философского вопрошания о человеке и его языке, хотя и не исключаем того технологического восторга, который охватывает нас в перспективе методологического обоснования антиязыковой коммуникации. Приведём соответствующий пример. Мы неоднократно указывали на лживый характер человеческой коммуникации, обусловленный, с одной стороны, самим «изначальным опозданием», а с другой - тем эволюционным свойством языка как семиотической системы, которая позволяет скрывать истинные намерения, говоря не то, что думается, и делать не то, что говорится. Естественно, что вся коммуникация не сводится к такому манипулированию, даже несмотря на наличие специальных лингво- и психометодик (например, нейролингвистического программирования), однако проблема нелживой коммуникации между людьми актуальна как никогда.

Если ложь неискоренима из вербальной коммуникации, но невсеобъемлюща, несмотря на то, что семантика желаний не формализована в соответствующую семиотику, то вероятным решением дискурсивной безответственности может стать использование технических устройств, в идеале рассчитанных на телепатическое общение, но на практике обнажающих внутреннюю речь коммуникантов по мере снижения интереса к манипуляции сознанием (ср. с экстравагантным пассажем Л. Витгенштейна [33, с. 310] и с феноменологическим аргументом Э. Гуссерля [34, с. 261]).

Если ложь в потоке сознания озвучивать в потоке речи, что означает переводить невербальный поток в вербальное русло, не смешивая невербальность с лживостью, а антиязыковость с бессознательностью, то благодаря этому удастся существенно сократить на субъективных препо- нах коммуникации, чтобы сосредоточиться на объективных помехах - например, принципе «изначального опоздания», который может оказаться всего лишь семиотической иллюзией, создающей квазипсихологические проблемы у носителей языка (ср.: [35]). Различая между планом референции (вещь), планом содержания (означаемое) и планом выражения (означающее), «изначальное опоздание» может быть сокращено до погрешности в силу самой произвольности (немотивированности) языкового знака. Не углубляясь в проблему семиотической немотивированности, зададимся вопросом: «А что может скрываться за перформативной номинацией помимо темпорального обоснования произвольности языкового знака?». Если перформативная номинация отлична от произвольности языкового знака, то сущность данного отличия должна заключаться в тождестве между вещью и понятием, а произвольность звуковой оболочки может быть вполне списана на темпоральность принципа «изначального опоздания»: с одной стороны, запаздыванию подвержено означаемое по отношению к референту, а с другой - означающее по отношению к означаемому, поэтому на уровне «референт - означаемое» произвольность языкового знака выражена меньше, чем на уровне «означаемое - означающее», что подводит к гипотезе о непроизвольности антиязыкового знака, для которого принцип «изначального опоздания» тщетен в том времени, какое образует смысловое пространство, различие в котором обеспечивается дискретностью (целочисленного?) веществования.

В последующих статьях мы продолжим рассмотрение проблемы телепатии как с точки зрения антиязыковой методологии, так и с позиции её материалистического обоснования. Психическая жизнь современных людей ещё по-прежнему сложна в сравнении с идущими им на смену трансхьюманами. Не исключено, что новые инженерные технологии позволят расширить телепатические возможности человека [1], максимально полно объективировав его субъективный мир (ср. с индивидуальной объективной реальностью [36; 37]). Однако нам кажется, что нужно успеть сохранить человеческую размерность поставленной проблемы, дабы не оказаться в ситуации, когда мы даже не будем осознавать, что уже перестали быть людьми [38, с. 810].

\section{Список литературы:}

1. Нилогов А. С. Антиязык как ясновидение в бессловесной коммуникации Д.Г. Беннета // Психология и психотехника. 2015. № 1. C. 92-103. (DOI: 10.7256/2070-8955.2015.1.13737)

2. Золотов Е.В. Телепатия: рукопись учебника. M., 1967. (URL: http://belsu.narod.ru/telepat/index.html, http://belsu. narod.ru/telepat/soderganie.htm, http://belsu.narod.ru/telepat/telepat1.htm, http://belsu.narod.ru/telepat/telepat2. 
htm, http://belsu.narod.ru/telepat/telepat25.htm\#, http://belsu.narod.ru/telepat/telepat30.htm\#1 (дата обращения: 22.11.2015))

3. Манев И.А. Почему малограмотная болгарская ясновидящая Ванга понимает любые незнакомые языки? // Психология и психотехника. 2009. № 10. С. 48-56.

4. Философский интернет-словарь: статья «Телепатия». (URL: http://enc-dic.com/philosophy/Telepatija-2342.html (дата обращения: 22.11.2015))

5. Ефимова И.Я. Парапсихология: миф или реальность?.. // Психология и психотехника. 2008. № 1. С. 22-27.

6. Википедия: статья «Телепатия». (URL: https://ru.wikipedia.org/wiki/\%D0\%A2\%D0\%B5\%D0\%BB\%D0\%B5\%D0\%BF\% D0\%B0\%D1\%82\%D0\%B8\%D1\%8F (дата обращения: 22.11.2015))

7. Desoille R. De quelques conditions auxquelles il faut satisfaire pour reussir des experiences de Telepathie provoquee // Revue Metapsychique. 1932. № 6.

8. Soal S.G. Modern Experiments in telepathy. New Haven, 1954.

9. Васильев Л.Л. «Внушение на расстоянии» (заметки физиолога). М., 1962.

10. Васильев Л.Л. Таинственные явления человеческой психики. М., 1964.

11. Bender H. Telepathic, Hellsehen und Psyhokinese. Munich, 1973.

12. Бехтерев В.М. Гипноз, внушение, телепатия. М., 1994.

13. Нилогов А.С. Философия антиязыка. СПб., 2013.

14. Гиренок Ф.И. Абсурд и речь. Антропология воображаемого. М., 2012.

15. Crow T.J. Is schizophrenia the price that Homo sapiens pays for language? // Schizophrenia Research. December $19,1997$. Volume 28. Issues 2-3. P. 127-141. (DOI: http://dx.doi.org/10.1016/S0920-9964(97)00110-2. URL: http://www.schresjournal.com/article/S0920-9964\%2897\%2900110-2/abstract?cc=y= (дата обращения: 22.11.2015))

16. Руднев В.П. Философия языка и семиотика безумия: Избранные работы. М., 2007.

17. Соссюр Ф. де. Курс общей лингвистики / Пер. с фр.; под ред. и с примеч. Р.И. Шор. М., 2004.

18. Деррида Ж. Письмо и различие / Пер. с франц. Д.Ю. Кралечкина; под ред. В.Ю. Кузнецова. М., 2000.

19. Декомб В. Современная французская философия: сб. / Пер. с франц. М.М. Фёдоровой. М., 2000.

20. Гурко Е.Н. Деконструкция: тексты и интерпретация. Деррида Ж. Оставь это имя (Постскриптум), Как избежать разговора: денегации. Минск, 2001.

21. Гаспарян Д.Э. Введение в неклассическую философию. М., 2011.

22. Президент России Д.А. Медведев об изначальном опоздании. 25.06.2010. (URL: http://www.youtube.com/ watch?v=YARiJdw6hxc, http://www.kremlin.ru/events/president/news/8169/videos (дата обращения: 22.11.2015))

23. НACA работает над чтением мыслей // Cnews: издание о высоких технологиях. 19.03.2004. (URL: http://www.cnews. ru/news/top/index.shtml?2004/03/19/156631 (дата обращения: 22.11.2015))

24. Шерток Л. Непознанное в психике человека. М., 1982.

25. Налимов В.В. Спонтанность сознания. Вероятностная теория смыслов и смысловая архитектоника личности. М., 2007.

26. Нилогов А.C. Сплю, следовательно, существую // Психология и психотехника. 2015. № 4. C. 373-382. (DOI: 10.7256/2070-8955.2015.4.14845)

27. Технический директор Google расписал будущее мира: прогноз до 2099 года // InfoResist. 20.04.2015. (URL: https://m. inforesist.org/texnicheskij-direktor-google-raspisal-budushhee-mira-prognoz-do-2099-goda/ (дата обращения: 22.11.2015))

28. Немов Р.С. Психология: Учеб. для студ. высш. пед. учеб. заведений: В 3 кн. Кн. 1: Общие основы психологии. М., 2003.

29. Телепатия стала реальностью: сюжет HTB от 28.03.2007. (URL: http://news.ntv.ru/106300/ (дата обращения: 22.11.2015))

30. Дамазио А.Р. Возвращаясь в прошлое // В мире науки. 2003. № 1. С. 52-59.

31. Муравьёва М. Чтение мыслей станет реальностью // Электронное издание «Наука и технологии России - STRF.ru». 17.04.2009. (URL: http://www.strf.ru/material.aspx?CatalogId=222\&d_no=19087\#.VlBnTr9W_EZ)/ (дата обращения: 22.11.2015))

32. Нилогов А.С., Кутырёв В.А. Последнее слово человека самому себе? (Беседа А.С. Нилогова с В.А. Кутырёвым) // Философия хозяйства. 2015. № 5. С. 172-189.

33. Витгенштейн Л. Философские работы. Часть I / Пер. с нем. М.С. Козловой и Ю.А. Асеева; сост., вступ. статья, примеч. М.С. Козловой. М., 1994.

34. Гуссерль Э. Идеи к чистой феноменологии и феноменологической философии. Книга первая / Пер. с нем. А.В. Михайлова; вступ. ст. В.А. Куренного. М., 2009.

35. Каратеев А.Ю. Человек и мир в концепции синхроничности // Психология и психотехника. 2008. № 2. С. 15-28.

36. Бескова И.А. Природа сновидений (эпистемологический анализ). М., 2005.

37. Нилогов А.С. Психология и философия антиязыка (на материале монографии И.А. Бесковой «Природа сновидений») // Психология и психотехника. 2015. № 6. C. 588-601. (DOI: 10.7256/2070-8955.2015.6.15111)

38. Нилогов А.С., Кутырёв В.А. Восстание техноидов: психология и философия постчеловечества // Психология и психотехника. 2015. № 8. C. 802-813. (DOI: 10.7256/2070-8955.2015.8.15763)

\section{References (transliteration):}

1. Nilogov A.S. Antiyazyk kak yasnovidenie v besslovesnoi kommunikatsii D.G. Benneta // Psikhologiya i psikhotekhnika. 2015. № 1. S. 92-103. (DOI: 10.7256/2070-8955.2015.1.13737) 


\section{Психология и психотехника 11(86) • 2015}

2. Zolotov E.V. Telepatiya: rukopis' uchebnika. M., 1967. (URL: http://belsu.narod.ru/telepat/index.html, http://belsu.narod.ru/ telepat/soderganie.htm, http://belsu.narod.ru/telepat/telepat1.htm, http://belsu.narod.ru/telepat/telepat2.htm, http:// belsu.narod.ru/telepat/telepat25.htm\#, http://belsu.narod.ru/telepat/telepat30.htm\#1 (data obrashcheniya: 22.11.2015))

3. Manev I.A. Pochemu malogramotnaya bolgarskaya yasnovidyashchaya Vanga ponimaet lyubye neznakomye yazyki? // Psikhologiya i psikhotekhnika. 2009. № 10. S. 48-56.

4. Filosofskii internet-slovar': stat'ya «Telepatiya». (URL: http://enc-dic.com/philosophy/Telepatija-2342.html (data obrashcheniya: 22.11.2015))

5. Efimova I.Ya. Parapsikhologiya: mif ili real'nost'?.. // Psikhologiya i psikhotekhnika. 2008. № 1. S. 22-27.

6. Vikipediya: stat'ya «Telepatiya». (URL: https://ru.wikipedia.org/wiki/\%D0\%A2\%D0\%B5\%D0\%BB\%D0\%B5\%D0\%BF\%D0 \%B0\%D1\%82\%D0\%B8\%D1\%8F (data obrashcheniya: 22.11.2015))

7. Desoille R. De quelques conditions auxquelles il faut satisfaire pour reussir des experiences de Telepathie provoquee // Revue Metapsychique. 1932. № 6.

8. Soal S.G. Modern Experiments in telepathy. New Haven, 1954.

9. Vasil'ev L.L. «Vnushenie na rasstoyanii» (zametki fiziologa). M., 1962.

10. Vasil'ev L.L. Tainstvennye yavleniya chelovecheskoi psikhiki. M., 1964.

11. Bender H. Telepathic, Hellsehen und Psyhokinese. Munich, 1973.

12. Bekhterev V.M. Gipnoz, vnushenie, telepatiya. M., 1994.

13. Nilogov A.S. Filosofiya antiyazyka. SPb., 2013.

14. Girenok F.I. Absurd i rech'. Antropologiya voobrazhaemogo. M., 2012.

15. Crow T.J. Is schizophrenia the price that Homo sapiens pays for language? // Schizophrenia Research. December $19,1997$. Volume 28. Issues 2-3. P. 127-141. (DOI: http://dx.doi.org/10.1016/S0920-9964(97)00110-2. URL: http://www.schresjournal.com/article/S0920-9964\%2897\%2900110-2/abstract?cc=y= (дата обращения: 22.11.2015))

16. Rudnev V.P. Filosofiya yazyka i semiotika bezumiya: Izbrannye raboty. M., 2007.

17. Sossyur F. de. Kurs obshchei lingvistiki / Per. s fr.; pod red. i s primech. R.I. Shor. M., 2004.

18. Derrida Zh. Pis'mo i razlichie / Per. s frants. D.Yu. Kralechkina, pod red. V.Yu. Kuznetsova. M., 2000.

19. Dekomb V. Sovremennaya frantsuzskaya filosofiya: sb. / Per. s frants. M.M. Fedorovoi. M., 2000.

20. Gurko E.N. Dekonstruktsiya: teksty i interpretatsiya. Derrida Zh. Ostav' eto imya (Postskriptum), Kak izbezhat' razgovora: denegatsii. Minsk, 2001.

21. Gasparyan D.E. Vvedenie v neklassicheskuyu filosofiyu. M., 2011.

22. Prezident Rossii D.A. Medvedev ob iznachal'nom opozdanii. 25.06.2010. (URL: http://www.youtube.com/ watch?v=YARiJdw6hxc, http://www.kremlin.ru/events/president/news/8169/videos (data obrashcheniya: 22.11.2015))

23. NASA rabotaet nad chteniem myslei // Cnews: izdanie o vysokikh tekhnologiyakh. 19.03.2004. (URL: http://www.cnews.ru/ news/top/index.shtml?2004/03/19/156631 (data obrashcheniya: 22.11.2015))

24. Shertok L. Nepoznannoe v psikhike cheloveka. M., 1982.

25. Nalimov V.V. Spontannost' soznaniya. Veroyatnostnaya teoriya smyslov i smyslovaya arkhitektonika lichnosti. M., 2007.

26. Nilogov A.S. Splyu, sledovatel’no, sushchestvuyu // Psikhologiya i psikhotekhnika. 2015. № 4. S. 373-382. (DOI: 10.7256/20708955.2015.4.14845)

27. Tekhnicheskii direktor Google raspisal budushchee mira: prognoz do 2099 goda // InfoResist. 20.04.2015. (URL: https://m. inforesist.org/texnicheskij-direktor-google-raspisal-budushhee-mira-prognoz-do-2099-goda/ (data obrashcheniya: 22.11.2015))

28. Nemov R.S. Psikhologiya: Ucheb. dlya stud. vyssh. ped. ucheb. zavedenii: V 3 kn. Kn. 1: Obshchie osnovy psikhologii. M., 2003.

29. Telepatiya stala real'nost'yu: syuzhet NTV ot 28.03.2007. (URL: http://news.ntv.ru/106300/ (data obrashcheniya: 22.11.2015))

30. Damazio A.R. Vozvrashchayas' v proshloe // V mire nauki. 2003. № 1. S. 52-59.

31. Murav'eva M. Chtenie myslei stanet real'nost'yu // Elektronnoe izdanie «Nauka i tekhnologii Rossii - STRF.ru». 17.04.2009. (URL: http://www.strf.ru/material.aspx?CatalogId=222\&d_no=19087\#.VlBnTr9W_EZ)/(data obrashcheniya: 22.11.2015))

32. Nilogov A.S., Kutyrev V.A. Poslednee slovo cheloveka samomu sebe? (Beseda A.S. Nilogova s V.A. Kutyrevym) // Filosofiya khozyaistva. 2015. № 5. S. 172-189.

33. Vitgenshtein L. Filosofskie raboty. Chast' I / Per. s nem. M.S. Kozlovoi i Yu.A. Aseeva; sost., vstup. stat'ya, primech. M.S. Kozlovoi. M., 1994.

34. Gusserl' E. Idei k chistoi fenomenologii i fenomenologicheskoi filosofii. Kniga pervaya / Per. s nem. A.V. Mikhailova; vstup. st. V.A. Kurennogo. M., 2009.

35. Karateev A.Yu. Chelovek i mir v kontseptsii sinkhronichnosti // Psikhologiya i psikhotekhnika. 2008. № 2. S. 15-28.

36. Beskova I.A. Priroda snovidenii (epistemologicheskii analiz). M., 2005.

37. Nilogov A.S. Psikhologiya i filosofiya antiyazyka (na materiale monografii I.A. Beskovoi «Priroda snovidenii») // Psikhologiya i psikhotekhnika. 2015. № 6. S. 588-601. (DOI: 10.7256/2070-8955.2015.6.15111)

38. Nilogov A.S., Kutyrev V.A. Vosstanie tekhnoidov: psikhologiya i filosofiya postchelovechestva // Psikhologiya i psikhotekhnika. 2015. № 8. S. 802-813. (DOI: 10.7256/2070-8955.2015.8.15763) 